\title{
Uso da ozonioterapia como tratamento adjuvante não cirúrgico para doenças periodontais: uma revisão integrativa da literatura
}

\author{
Use of ozone therapy as a non-surgical adjuvant treatment for periodontal diseases: an integrative
}

\section{literature review}

\author{
Uso de la ozonoterapia como tratamiento adyuvante no quirúrgico de las enfermedades \\ periodontales: una revisión integradora de la literatura
}

Recebido: 10/11/2021 | Revisado: 18/11/2021 | Aceito: 23/11/2021 | Publicado: 05/12/2021

Lucas Andeilson dos Santos Matos
ORCID: https://orcid.org/0000-0001-6258-7327
Centro Universitário Fametro, Brasil
E-mail: lucasmmatos@outlook.com
Rafaela Alves Castro
ORCID: https://orcid.org/0000-0001-9518-0881
Centro Universitário Fametro, Brasil
E-mail: rafaelacastro.odonto@gmail.com
Jonatan Costa Gomes
ORCID: https://orcid.org/0000-0002-6741-1045
Universidade Federal do Mato Grosso, Brasil
E-mail: jonatanfaen@yahoo.com.br

\begin{abstract}
Resumo
O estudo ora conduzido tem como objetivo evidenciar os efeitos da terapia com ozônio como um tratamento integrativo e complementar não cirúrgico para doenças periodontais. Trata-se de uma revisão integrativa da literatura, na qual foram feitas buscas nas bases de dados Medline, Lilacs, EBSCOHost e Cochrane, utilizando os descritores "ozone", "ozone therapy" e "periodontal disease" publicados entre 2011 e 2021, sendo eleitos 20 artigos para compor o estudo. O ozônio é um gás formado por três átomos de oxigênio e, devido à sua instabilidade, é considerado um dos maiores agentes oxidantes do mundo, o que permite que este gás seja usado para diversos fins terapêuticos. Esta substância possui importantes efeitos antimicrobianos contra bactérias gram-negativas, que desempenham um forte papel na etiologia das doenças periodontais. Somando-se, ainda, possui um amplo espectro de atividade, mas com baixa toxicidade e não causa resistência bacteriana. A ozonioterapia mostra-se como um eficiente tratamento integrativo e complementar à raspagem e alisamento radicular, que por vezes pode ser insuficiente no tratamento das doenças periodontais. Contudo, novos estudos devem ser realizados para avaliar e determinar os parâmetros clínicos do ozônio.
\end{abstract}

Palavras-chave: Ozônio; Ozonioterapia; Doença periodontal.

\begin{abstract}
The present study aims to highlight the effects of ozone therapy as an integrative and non-surgical complementary treatment for periodontal diseases. This is an integrative literature review, in which Medline, Lilacs, EBSCOHost and Cochrane databases were searched, using the descriptors "ozone", "ozone therapy" and "periodontal disease" published between 2011 and 2021, being chosen 20 articles to compose the study. Ozone is a gas formed by three oxygen atoms and, due to its instability, it is considered one of the largest oxidizing agents in the world, which allows this gas to be used for various therapeutic purposes. This substance has important antimicrobial effects against gramnegative bacteria, which play a strong role in the etiology of periodontal diseases. In addition, it has a broad spectrum of activity, but with low toxicity and does not cause bacterial resistance. Ozone therapy is an efficient integrative treatment that complements scaling and root planing, which can sometimes be insufficient in the treatment of periodontal diseases. However, further studies must be carried out to assess and determine clinicians' parameters of ozone.
\end{abstract}

Keywords: Ozone; Ozone therapy; Periodontal disease.

\section{Resumen}

El presente estudio tiene como objetivo destacar los efectos de la ozonoterapia como tratamiento complementario integrador y no quirúrgico de las enfermedades periodontales. Se trata de una revisión integradora de la literatura, en la que se realizaron búsquedas en las bases de datos Medline, Lilacs, EBSCOHost y Cochrane, utilizando los 
descriptores "ozono", "ozonoterapia" y "enfermedad periodontal" publicados entre 2011 y 2021, siendo seleccionados 20 artículos para componer el estudio. El ozono es un gas formado por tres átomos de oxígeno y, debido a su inestabilidad, es considerado uno de los agentes oxidantes más grandes del mundo, lo que permite que este gas sea utilizado para diversos fines terapéuticos. Esta sustancia tiene importantes efectos antimicrobianos contra las bacterias gramnegativas, que juegan un papel importante en la etiología de las enfermedades periodontales. Además, tiene un amplio espectro de actividad, pero de baja toxicidad y no provoca resistencias bacterianas. La ozonoterapia es un tratamiento integrador eficaz que complementa el raspado y alisado radicular, que en ocasiones pueden resultar insuficientes en el tratamiento de las enfermedades periodontales. Sin embargo, se deben realizar más estudios para evaluar y determinar los parámetros clínicos del ozono.

Palabras clave: Ozono; Terapia de ozono; Enfermedad periodontal.

\section{Introdução}

As doenças periodontais englobam uma grande variedade de fenótipos clínicos, caracterizadas por processos inflamatórios crônicos, que são induzidos principalmente pela formação da placa bacteriana na superfície do dente, desencadeando sinais clínicos de inflamação observáveis na gengiva. A gengivite surge do acúmulo de placa dentária nos dentes, correspondendo a um complexo biofilme de bactérias imerso em uma matriz polimérica. Se não houver uma rotina de higiene oral adequada, poderá ocorrer a deposição de biofilme na margem gengival, que causará a mineralização deste material, denominado cálculo dental, sendo este um dos fatores causais para a periodontite, uma condição mais severa (Talmaç \& Çalişisi, 2021).

A periodontite é uma doença inflamatória destrutiva do periodonto, caracterizada pela destruição do tecido de suporte do dentário (cemento, ligamento periodontal e osso alveolar), ocorrendo interações entre os sistemas inflamatório e imunológico. Embora a inflamação periodontal seja iniciada por componentes do biofilme subgengival, a produção e a liberação de agentes inflamatórios são gerados e controlados pelo hospedeiro. As respostas aos microrganismos são os principais responsáveis pela degradação periodontal (Alinca, Sağlam, Celik, Hacisalihoglu \& Doğan, 2020).

Nesse sentido, percebe-se a necessidade de intervenções para interromper a progressão da inflamação e prevenir o acometimento da periodontite. O tratamento mais comum realizado é a instrução de higiene oral associada à raspagem $\mathrm{e}$ alisamento radicular, uma terapia não cirúrgica que tem como objetivo remover a placa bacteriana e o cálculo dentário, reduzindo o processo inflamatório. Deste modo, este tratamento pode ser realizado de forma manual, utilizando as curetas, ou também, com o método eletrônico, utilizando o ultrassom periodontal. No entanto, devido à anatomia radicular, a raspagem não elimina completamente as bactérias patogênicas, em especial nas concavidades radiculares, furcas, áreas interproximais e áreas com bolsas periodontais profundas, que são de difícil acesso ao instrumental utilizado (Y1lmaz et al., 2013).

Portanto, estratégias de tratamentos adjuvantes têm sido propostas, a fim de suprimir ou eliminar patógenos periodontais e controlar seu crescimento excessivo. Assim, as práticas integrativas e complementares em saúde podem exercer um papel fundamental na terapia periodontal. Dentre elas, a ozonioterapia tem crescido seu escopo de atuação na odontologia, sendo utilizada para diversos fins, mediante a concentração estabelecida (Tasdemir, Oskaybas, Alkan \& Cakmak, 2019; Colombo et al., 2021).

O primeiro registro da utilização do ozônio na odontologia foi em meados de 1930, época em que o cirurgião-dentista Edward A. Fisch fez uso da água ozonizada para efeitos desinfetantes, como antes de cirurgias orais e para cicatrização de feridas, pois o ozônio eleva a expressão de citocinas e interferons que auxiliam na reparação tecidual (Rosell, Femenías \& Capote, 2019).

Diante do exposto, por meio de uma revisão integrativa da literatura, o presente estudo tem como objetivo evidenciar os efeitos da terapia com ozônio, como um tratamento integrativo e complementar não cirúrgico para doenças periodontais. 


\section{Metodologia}

O estudo foi desenvolvido por meio de fontes indexadas nas bases de dados Medical Literature Analysis and Retrival System Online (MEDLINE), Literatura Latino Americana e do Caribe em Ciências da Saúde (LILACS), EBSCOHost e Cochrane Library, onde foi realizado um cruzamento entre os descritores "ozone", "ozone therapy" e "periodontal disease".

Os critérios de inclusão adotados foram: a) artigos nos idiomas inglês e espanhol; b) disponíveis na íntegra; c) publicados nos últimos onze anos; d) estudos clínicos, randomizados, unicêntrico, in vivo, in vitro e relato de caso; e) que atendessem à questão norteadora: utilização do ozônio como uma terapia adjuvante no tratamento das doenças periodontais. Já os critérios de exclusão foram: f) artigos de revisão, teses, dissertações, monografias; g) artigos duplicados; h) estudos não pertinentes ao tema.

Fluxograma 1 - Artigos encontrados.

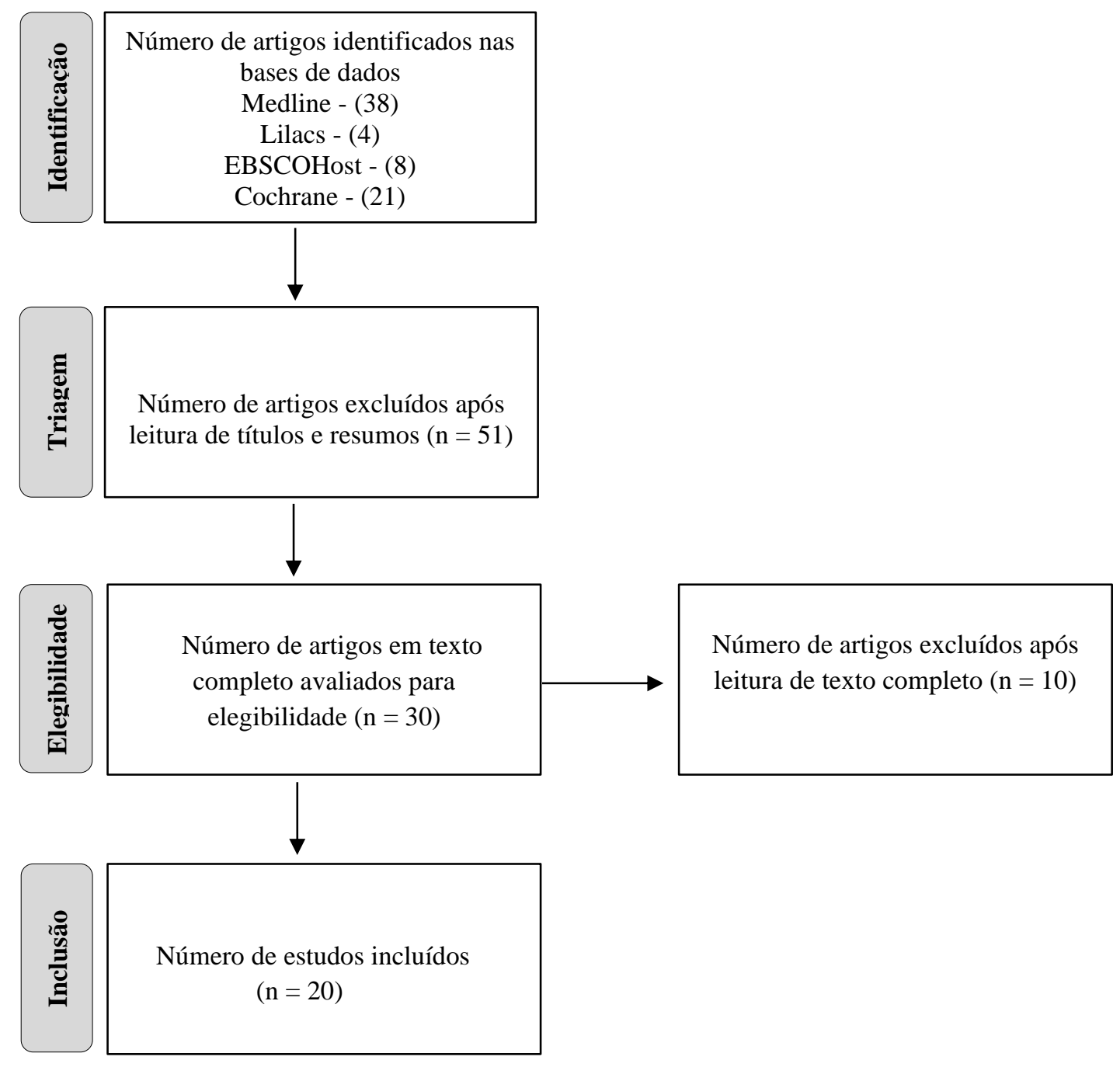

Fonte: Autores.

\section{Resultados}

Após buscas bibliográficas, gerou-se um total de 71 publicações, distribuídas pela Medline (38), Lilacs (4), EBSCOHost (8) e Cochrane (21), em que foi efetuada a leitura de títulos e resumos, sendo pré-selecionados 15 artigos. Assim, foi realizada a leitura dos artigos na íntegra e com base nos critérios de elegibilidade estabelecidos. Feito isso, excluíram-se 51 
e foram eleitos 20 para compor este estudo, sendo 14 ensaios clínicos randomizados, 3 estudos in vivo, 1 estudo in vitro, 1 relato de caso clínico e 1 estudo clínico unicêntrico, publicados entre 2011 e 2021 (Quadro 1).

Quadro 1 - Artigos selecionados para estudo.

\begin{tabular}{|c|c|c|c|}
\hline $\begin{array}{l}\text { AUTOR } \\
\text { PRINCIPAL/ } \\
\text { ANO } \\
\end{array}$ & $\begin{array}{l}\text { METODOLOGIA } \\
\text { DO ESTUDO }\end{array}$ & OBJETIVO & PRINCIPAIS RESULTADOS \\
\hline $\begin{array}{l}\text { Al- } \\
\text { Habashneh, } \\
2015\end{array}$ & $\begin{array}{l}\text { Ensaio clínico } \\
\text { randomizado }\end{array}$ & $\begin{array}{l}\text { Determinar os efeitos clínicos e biológicos do uso } \\
\text { adjuvante de ozônio no tratamento periodontal } \\
\text { não cirúrgico. }\end{array}$ & $\begin{array}{l}\text { A irrigação com água ozonizada como terapia adjuvante a } \\
\text { raspagem e alisamento radicular não produz nenhum } \\
\text { benefício estatisticamente significativo em comparação } \\
\text { com a raspagem e irrigação com água destilada. }\end{array}$ \\
\hline Alinca, 2020 & In vivo & $\begin{array}{l}\text { Investigar os efeitos da ozonioterapia e terapia a } \\
\text { laser de baixa intensidade na destruição óssea } \\
\text { induzida por doença periodontal em ratos com } \\
\text { periodontite induzida experimentalmente. }\end{array}$ & $\begin{array}{l}\text { Embora ambos os tratamentos tenham produzido efeitos } \\
\text { positivos, a terapia a laser de baixa intensidade parece ser } \\
\text { mais eficaz para aumentar a formação óssea alveolar. }\end{array}$ \\
\hline $\begin{array}{l}\text { Colombo, } \\
2021\end{array}$ & $\begin{array}{l}\text { Ensaio clínico } \\
\text { randomizado }\end{array}$ & $\begin{array}{l}\text { Avaliar a eficácia do gel ozonizado associado à } \\
\text { raspagem e alisamento radicular em relação a } \\
\text { raspagem e alisamento radicular com o gel de } \\
\text { clorexidina. }\end{array}$ & $\begin{array}{l}\text { Foi avaliado que o uso do gel ozonizado em adição a } \\
\text { raspagem e alisamento radicular não apresentou diferenças } \\
\text { significativas se comparado à raspagem e alisamento } \\
\text { radicular associado à clorexidina convencional. }\end{array}$ \\
\hline $\begin{array}{l}\text { Dengizek, } \\
2019\end{array}$ & $\begin{array}{l}\text { Ensaio clínico } \\
\text { randomizado }\end{array}$ & $\begin{array}{l}\text { Avaliar os efeitos clínicos e bioquímicos (estresse } \\
\text { oxidativo e mediadores pró-inflamatórios) do uso } \\
\text { de ozônio gasoso acompanhado de raspagem e } \\
\text { planejamento radicular no tratamento periodontal. }\end{array}$ & $\begin{array}{l}\text { Os resultados deste estudo indicam que a raspagem e } \\
\text { alisamento radicular aliada ao ozônio gasoso, quando } \\
\text { comparada a raspagem e alisamento radicular sozinha, não } \\
\text { se correlacionam com uma melhora significativa na } \\
\text { recuperação periodontal. }\end{array}$ \\
\hline Dhingra, 2011 & $\begin{array}{l}\text { Estudo clínico } \\
\text { unicêntrico }\end{array}$ & $\begin{array}{l}\text { Avaliar os efeitos clínicos de uma única irrigação } \\
\text { subgengival com água ozonizada na inflamação } \\
\text { gengival em pacientes ortodônticos e também } \\
\text { correlacionar os efeitos clínicos com a atividade } \\
\text { da enzima lactato desidrogenase no fluido das } \\
\text { fendas gengivais. }\end{array}$ & $\begin{array}{l}\text { Uma única irrigação subgengival de } 0,01 \mathrm{mg} \text { de água } \\
\text { ozonizada pode reduzir efetivamente a inflamação gengival } \\
\text { em pacientes ortodônticos, o que também se reflete na } \\
\text { redução dos níveis da enzima LDH. }\end{array}$ \\
\hline $\begin{array}{l}\text { Hayakumo, } \\
2013\end{array}$ & $\begin{array}{l}\text { Ensaio clínico } \\
\text { randomizado }\end{array}$ & $\begin{array}{l}\text { Avaliar os efeitos clínicos e microbiológicos da } \\
\text { irrigação água com nano bolhas de ozônio como } \\
\text { adjuvante do desbridamento subgengival para o } \\
\text { tratamento periodontal. }\end{array}$ & $\begin{array}{l}\text { O presente estudo sugere que a irrigação subgengival com } \\
\text { água com nano bolhas de ozônio pode ser um complemento } \\
\text { valioso para o tratamento periodontal. }\end{array}$ \\
\hline Kist, 2017 & $\begin{array}{l}\text { Ensaio clínico } \\
\text { randomizado }\end{array}$ & $\begin{array}{l}\text { Avaliar a eficácia de um gás ozônio ou protocolo } \\
\text { de desinfeçãa NaOCl / CHX foi comparada no } \\
\text { tratamento de canal radicular da periodontite } \\
\text { apical. }\end{array}$ & $\begin{array}{l}\text { Os protocolos de gás ozônio e } \mathrm{NaOCl} / \mathrm{CHX} \text { aqui usados } \\
\text { não mostraram diferença na redução bacteriana nas áreas } \\
\text { amostradas dos canais radiculares. }\end{array}$ \\
\hline $\begin{array}{l}\text { Makeeva, } \\
2015\end{array}$ & Relato de caso clínico & $\begin{array}{l}\text { Relatar a abordagem interdisciplinar entre o } \\
\text { endodontista e periodontista para o tratamento } \\
\text { bem-sucedido de uma lesão endo-perio em um } \\
\text { paciente com periodontite agressiva no canino } \\
\text { inferior direito usando terapia de ozônio para } \\
\text { bolsa periodontal e tratamento de canal radicular. }\end{array}$ & $\begin{array}{l}\text { A terapia com ozônio é benéfica para o tratamento bem- } \\
\text { sucedido de lesões endo-perio com bolsas periodontais } \\
\text { estreitas em pacientes com periodontite agressiva e mau } \\
\text { prognóstico. }\end{array}$ \\
\hline Nicolini, 2021 & $\begin{array}{l}\text { Ensaio clínico } \\
\text { randomizado }\end{array}$ & $\begin{array}{l}\text { Avaliar o efeito da água ozonizada na formação } \\
\text { inicial da placa e na inflamação gengival. }\end{array}$ & $\begin{array}{l}\text { A água ozonizada parece não afetar a formação de } \\
\text { biofilmes supra e subgengivais, bem como a inflamação } \\
\text { gengival. }\end{array}$ \\
\hline Pandya, 2016 & In vitro & $\begin{array}{l}\text { Avaliar as alterações clínicas e microbianas por } \\
\text { irrigação subgengival com diferentes irrigantes } \\
\text { subgengivais em pacientes com periodontite e } \\
\text { também avaliar o efeito mecânico de diferentes } \\
\text { dispositivos de irrigação local, caso existam. }\end{array}$ & $\begin{array}{l}\text { Dentro dos limites e escopo do estudo, pode-se concluir } \\
\text { com segurança que a clorexidina } 0,2 \% \text { pode ser usada como } \\
\text { adjuvante à terapia mecânica para obter uma redução } \\
\text { significativa nas alterações periodontais inflamatórias e } \\
\text { também na microflora periodontopatogênica. }\end{array}$ \\
\hline Patel, 2012 & $\begin{array}{l}\text { Ensaio clínico } \\
\text { randomizado }\end{array}$ & $\begin{array}{l}\text { Avaliar os efeitos terapêuticos do óleo ozonizado } \\
\text { tópico na cicatrização precoce de locais cirúrgicos } \\
\text { de enxerto gengival livre. }\end{array}$ & $\begin{array}{l}\text { Obteve-se uma grande melhora na cicatrização epitelial e } \\
\text { na saúde gengival após a aplicação tópica de óleo vegetal } \\
\text { tratado com ozônio em locais cirúrgicos gengivais. }\end{array}$ \\
\hline Patel, 2011 & In vivo & $\begin{array}{l}\text { Avaliar o efeito do óleo ozonizado em feridas } \\
\text { palatinas. }\end{array}$ & $\begin{array}{l}\text { Obteve-se uma melhora significativa no tamanho da ferida } \\
\text { e na cicatrização epitelial após a aplicação de óleo } \\
\text { ozonizado tópico em comparação com o óleo de controle } \\
\text { em feridas palatinas. }\end{array}$ \\
\hline Ranjith, 2021 & $\begin{array}{l}\text { Ensaio clínico } \\
\text { randomizado }\end{array}$ & $\begin{array}{l}\text { Descobrir o benefício da irrigação com água } \\
\text { ozonizada juntamente com a terapia periodontal } \\
\text { não cirúrgica para o tratamento da periodontite. }\end{array}$ & $\begin{array}{l}\text { A irrigação com ozônio fornece benefício adjuvante junto } \\
\text { com a terapia periodontal não cirúrgica na redução dos } \\
\text { parâmetros clínicos e mediadores inflamatórios na saliva. }\end{array}$ \\
\hline Rapone, 2020 & $\begin{array}{l}\text { Ensaio clínico } \\
\text { randomizado }\end{array}$ & $\begin{array}{l}\text { Comparar a eficácia clínica de uma intervenção } \\
\text { periodontal intensiva consistindo de tratamento } \\
\text { periodontal convencional em conjunto com } \\
\text { terapia com gás ozônio na redução do nível de } \\
\text { hemoglobina glicada em pacientes diabéticos tipo } \\
2 \text { e tratamento periodontal padrão. }\end{array}$ & $\begin{array}{l}\text { Embora a mudança não tenha sido significativa, o } \\
\text { tratamento periodontal associado à terapia com ozônio } \\
\text { gasoso tende a reduzir os níveis de hemoglobina glicada. }\end{array}$ \\
\hline Rosell, 2019 & $\begin{array}{l}\text { Ensaio clínico } \\
\text { randomizado }\end{array}$ & $\begin{array}{l}\text { Avaliar a eficácia do oleozon tópico no } \\
\text { tratamento da gengivite fibroedematosa crônica. }\end{array}$ & $\begin{array}{l}\text { Não foram encontradas diferenças significativas em relação } \\
\text { à eficácia do oleozon e da clorexidina tópicos no tratamento } \\
\text { da gengivite fibroedematosa crônica, ambos os tratamentos }\end{array}$ \\
\hline
\end{tabular}




\begin{tabular}{|c|c|c|c|}
\hline & & & foram igualmente eficazes na maioria dos casos. \\
\hline Saglam, 2019 & In vivo & $\begin{array}{l}\text { Determinar o efeito da aplicação sistêmica e } \\
\text { tópica de ozônio na perda óssea alveolar, } \\
\text { avaliando o efeito do fator-1-alfa induzível por } \\
\text { hipóxia (HIF-1- } \alpha \text { ) e ativador do receptor de } \\
\text { células positivas para ligante NF-kB (RANKL) } \\
\text { em alterações histopatológicas e e } \\
\text { imunohistoquímicas em um modelo de } \\
\text { periodontite em rato. }\end{array}$ & $\begin{array}{l}\text { Ambas as aplicações de ozônio diminuíram as contagens de } \\
\text { células RANKL-positivas, a aplicação de TO diminuiu } \\
\text { HIF-1- } \alpha \text { a contagem de células positivas e a aplicação de } \\
\text { (grupo de ozônio sistêmico) SO, foram mais eficazes na } \\
\text { redução de ABL em comparação com o grupo de controle. }\end{array}$ \\
\hline Talmaç, 2021 & $\begin{array}{c}\text { Ensaio clínico } \\
\text { randomizado }\end{array}$ & $\begin{array}{l}\text { Investigar os efeitos da aplicação de ozônio } \\
\text { durante o procedimento de escalonamento sobre } \\
\text { os parâmetros clínicos da gengivite em fumantes } \\
\text { e não fumantes e para investigar a eficácia do gás } \\
\text { ozônio no tratamento periodontal. }\end{array}$ & $\begin{array}{l}\text { Os fortes efeitos antimicrobianos e antiinflamatórios do } \\
\text { ozônio, sua capacidade de estimular o sistema circulatório e } \\
\text { modular a resposta imune, fazem do ozônio um agente } \\
\text { terapêutico preferido para o tratamento de patologias orais e } \\
\text { doenças periodontais. }\end{array}$ \\
\hline $\begin{array}{l}\text { Tasdemir, } \\
2019\end{array}$ & $\begin{array}{c}\text { Ensaio clínico } \\
\text { randomizado }\end{array}$ & $\begin{array}{l}\text { Avaliar os efeitos da terapia com ozônio nos } \\
\text { parâmetros clínicos e bioquímicos de pacientes } \\
\text { com periodontite generalizada, moderada e grave, } \\
\text { após terapia periodontal não cirúrgica. }\end{array}$ & $\begin{array}{l}\text { A terapia com ozônio não teve nenhum efeito adicional nos } \\
\text { parâmetros periodontais. Todas as citocinas foram } \\
\text { reduzidas após a terapia periodontal. Apenas os níveis de } \\
\text { PTX-3 foram significativamente mais baixos nos locais de } \\
\text { ozônio. }\end{array}$ \\
\hline $\begin{array}{l}\text { Tasdemir, } \\
2016\end{array}$ & $\begin{array}{c}\text { Ensaio clínico } \\
\text { randomizado }\end{array}$ & $\begin{array}{l}\text { Analisar os efeitos da terapia com ozônio no } \\
\text { período de cicatrização precoce de enxertos } \\
\text { gengivais epitelizados colocados para aumento } \\
\text { gengival sem cobertura radicular por fluxometria } \\
\text { de laser Doppler. }\end{array}$ & $\begin{array}{l}\text { A terapia com ozônio aumentou as unidades de perfusão } \\
\text { sanguínea na primeira semana pós-operatória. Como } \\
\text { também a melhora na cicatrização de feridas acompanhada } \\
\text { por um aumento na qualidade de vida e diminuição na dor } \\
\text { pós-operatória. }\end{array}$ \\
\hline Yilmaz, 2013 & $\begin{array}{l}\text { Ensaio clínico } \\
\text { randomizado }\end{array}$ & $\begin{array}{l}\text { Avaliar os resultados clínicos e microbiológicos } \\
\text { do tratamento com o laser Er: YAG e aplicação } \\
\text { tópica de ozônio gasoso como adjuvantes à } \\
\text { terapia periodontal inicial em pacientes com } \\
\text { periodontite crônica (PC). }\end{array}$ & $\begin{array}{l}\text { Embora estatisticamente não significativo, o fato de que a } \\
\text { mudança anaeróbia obrigatória foi observada } \\
\text { principalmente no grupo de laser SRP + Er: YAG, e uma } \\
\text { diminuição semelhante foi observada no grupo de SRP + } \\
\text { ozônio gasoso tópico, mostra que o ozônio tem um efeito } \\
\text { antimicrobiano equivalente ao de o laser Er: YAG. }\end{array}$ \\
\hline
\end{tabular}

Fonte: Autores.

\section{Discussão}

O ozônio é um gás de cor azul claro abundante na estratosfera, formado por três átomos de oxigênio que podem ser usados nas formas gasosa e líquida (dissolvida em água e óleo). Ele é produzido por um gerador de ozônio, dispositivo que capta o oxigênio e, através de uma onda elétrica, transforma a molécula de $\mathrm{O} 2 \mathrm{em} \mathrm{O}$. Devido à grande instabilidade deste gás, ele é considerado um dos maiores agentes oxidantes do mundo e essa propriedade permite que o ozônio seja usado para diversos fins terapêuticos (Alinca et al., 2020).

Somando ainda, este gás possui efeito analgésico, anti-inflamatório e aumenta a oxigenação tecidual, elevando a atividade funcional e o potencial de regeneração tecidual. Em baixa concentração, o ozônio apresenta efeito analgésico que pode ser empregado, por exemplo, no tratamento de dores associadas às disfunções temporomandibulares. Em média concentração, pode ser usado como anti-inflamatório na endodontia, para diminuir a ação dos mediadores inflamatórios intrarradiculares. Já em alta concentração, pode ser aplicado em áreas necróticas, devido à sua ação antimicrobiana (Tasdemir et al., 2019; Colombo et al., 2021).

A terapia com ozônio também promove importantes efeitos antimicrobianos contra fungos, protozoários, vírus e espécies bacterianas, como bactérias gram-negativas, que desempenham um papel na etiologia das doenças periodontais. O ozônio exerce esse efeito, induzindo a destruição das membranas citoplasmáticas e paredes celulares de bactérias e fungos periodontopatógenos. Também possui um amplo espectro de atividade, mas com baixa toxicidade e não causa resistência, dando uma vantagem a esse tratamento local, quando comparado ao sistêmico com o uso dos antibióticos (Talmaç \& Çalişir, 2021).

O ozônio demostrou aumentar a liberação de óxido nítrico (NO), levando à vasodilatação e um maior fluxo sanguíneo nos tecidos, como também, induz a gradação de radicais de oxigênio livre, levando a uma mudança nos níveis de enzimas antioxidantes e na atividade do sistema imunológico. Com isso, a ozonioterapia pode ser utilizada para o tratamento de condições fisiopatológicas nas quais o processo inflamatório é intenso e o sistema imunológico é acionado. A terapia com 
ozônio melhora a inflamação na região por meio da oxigenação tecidual, influenciando positivamente os desfechos da doença periodontal (Saglam, Alinca, Celik, Hacisalihoglu, \& Dogan, 2019).

Através de ensaio clínico randomizado, Dengizek et al. (2019) puderam observar que a raspagem e alisamento radicular, aliados ao ozônio, aplicados em bolsas periodontais, demonstraram efeitos semelhantes quando comparados apenas com a realização da raspagem, não havendo alterações nos marcadores bioquímicos e indicadores de recuperação clínica. Contudo, Makeeva, Daurova, Byakova e Turkina (2020) obtiveram sucesso clínico utilizando o gás de ozônio no tratamento de um paciente com lesão endo-periodontal, que apresentava bolsas periodontais estreitas de difícil acesso para tratamento convencional sem procedimento cirúrgico, havendo uma melhora dos parâmetros clínicos e redução na contagem bacteriana em quadrantes tratados por raspagem e alisamento radicular aliada à ozonioterapia.

Patel, Kumar, Kumar, Gd e Patel, (2011) em seu estudo in vivo, avaliaram o efeito do óleo ozonizado em feridas palatinas e observou-se um aumento significativo na reepitelização das feridas do local doador palatino após a aplicação de óleo ozonizado tópico em comparação com outros óleos sem ozônio. Patel et al. (2012) reitera em um ensaio clínico randomizado, que aplicaram óleo ozonizado em sítios cirúrgicos de enxerto gengival livre (sítio enxertado e sítio doador palatino). Os autores relataram que as alterações regenerativas observadas após a aplicação tópica do óleo ozonizado nas células epiteliais do tecido em cicatrização foram significativas, resultando em rápida queratinização e melhor cicatrização do tecido gengival.

Dhingra e Vandana (2011) objetivaram avaliar em seu estudo unicêntrico os efeitos clínicos de uma única irrigação subgengival de $0,01 \mathrm{mg}$ com água ionizada em pacientes ortodônticos e foi observado que com a utilização da água ionizada pode-se reduzir efetivamente os níveis de gengivite durante o tratamento ortodôntico. Ademais, Hayakumo, Arakawa, Mano e Izumi (2013) em ensaio clínico randomizado, avaliaram os efeitos clínicos e microbiológicos da irrigação água com nano bolhas de ozônio como adjuvante do debridamento subgengival para o tratamento periodontal. O estudo concluiu que a irrigação subgengival com água ozonizada pode ser um complemento valioso para o tratamento periodontal.

\section{Conclusão}

Nesse sentido, é possível analisar que o tratamento das doenças periodontais utilizando a raspagem e alisamento radicular apresentam bons resultados clínicos, porém, por vezes, pode ser insuficiente devido à anatomia radicular apresentada. Deste modo, a ozonioterapia mostra-se como um eficiente tratamento integrativo e complementar, em que seus efeitos antimicrobianos e anti-inflamatórios estimulam o sistema circulatório e modulam a resposta imune, agindo contra produtores de biofilme e bactérias resistentes a antibióticos, fazendo do ozônio um agente terapêutico promissor no tratamento de doenças periodontais.

Outrossim, novos estudos clínicos de acompanhamentos prolongados devem ser realizados, para avaliar o efeito a longo prazo da utilização do ozônio e seus possíveis efeitos colaterais, como também determinar os parâmetros para uso clínico da substância, como valores de dosagem, duração e frequência para o tratamento de afecções periodontais.

\section{Agradecimentos}

Agradecemos a todos que direta e indiretamente contribuíram para a realização e sucesso do artigo.

\section{Referências}

Al-Habashneh, R., Alsalman, W., \& Khader, Y. (2015). Ozone as an adjunct to conventional nonsurgical therapy in chronic periodontitis: a randomized controlled clinical trial. Journal of periodontal research, 50(1), 37-43. https://doi.org/10.1111/jre.12177 
Alinca, S. B., Sağlam, E., Celik, T. Z., Hacisalihoglu, P., \& Doğan, M. A. (2020). Is low level laser therapy or ozone therapy more effective for bone healing? Understanding the mechanisms of HIF-1 $\alpha$, RANKL and OPG. Biotechnic \& histochemistry : official publication of the Biological Stain Commission, 95(8), 597-604. https://doi.org/10.1080/10520295.2020.1743360

Colombo, M., Gallo, S., Garofoli, A., Poggio, C., Arciola, C. R., \& Scribante, A. (2021). Ozone Gel in Chronic Periodontal Disease: A Randomized Clinical Trial on the Anti-Inflammatory Effects of Ozone Application. Biology, 10(7), 625. https://doi.org/10.3390/biology10070625

Dengizek, E. S, Serkan, D., Abubekir, E., Bay, K. A., Onder, O., \& Arife, C. (2019). Evaluating clinical and laboratory effects of ozone in non-surgical periodontal treatment: a randomized controlled trial. Journal of applied oral science: revista FOB, 27, e20180108. https://doi.org/10.1590/1678-7757-20180108

Dhingra, K., \& Vandana, K. L. (2011). Management of gingival inflammation in orthodontic patients with ozonated water irrigation--a pilot study. International journal of dental hygiene, 9(4), 296-302. https://doi.org/10.1111/j.1601-5037.2011.00506.x

Hayakumo, S., Arakawa, S., Mano, Y., \& Izumi, Y. (2013). Clinical and microbiological effects of ozone nano-bubble water irrigation as an adjunct to mechanical subgingival debridement in periodontitis patients in a randomized controlled trial. Clinical oral investigations, 17(2), 379-388. https://doi.org/10.1007/s00784-012-0711-7

Kist, S., Kollmuss, M., Jung, J., Schubert, S., Hickel, R., \& Huth, K. C. (2017). Comparison of ozone gas and sodium hypochlorite/chlorhexidine two-visit disinfection protocols in treating apical periodontitis: a randomized controlled clinical trial. Clinical oral investigations, 21(4), 995-1005. https://doi.org/10.1007/s00784-016-1849-5

Makeeva, M. K., Daurova, F. Y., Byakova, S. F., \& Turkina, A. Y. (2020). Treatment of an Endo-Perio Lesion with Ozone Gas in a Patient with Aggressive Periodontitis: A Clinical Case Report and Literature Review. Clinical, cosmetic and investigational dentistry, 12, 447-464. https://doi.org/10.2147/CCIDE.S267933

Nicolini, A. C., Rotta, I., Langa, G., Friedrich, S. A., Arroyo-Bonilla, D. A., Wagner, M. C., Weidlich, P., Rösing, C. K., \& Cavagni, J. (2021). Efficacy of ozonated water mouthwash on early plaque formation and gingival inflammation: a randomized controlled crossover clinical trial. Clinical oral investigations, 25(3), 1337-1344. https://doi.org/10.1007/s00784-020-03441-y

Pandya, D. J., Manohar, B., Mathur, L. K., \& Shankarapillai, R. (2016). Comparative evaluation of two subgingival irrigating solutions in the management of periodontal disease: A clinicomicrobial study. Journal of Indian Society of Periodontology, 20(6), 597-602. https://doi.org/10.4103/jisp.jisp_328_16

Patel, P. V., Kumar, S., Vidya, G. D., Patel, A., Holmes, J. C., \& Kumar, V. (2012). Cytological assessment of healing palatal donor site wounds and grafted gingival wounds after application of ozonated oil: an eighteen-month randomized controlled clinical trial. Acta cytologica, 56(3), 277-284. https://doi.org/10.1159/000336889

Patel, P. V., Kumar, V., Kumar, S., Gd, V., \& Patel, A. (2011). Therapeutic effect of topical ozonated oil on the epithelial healing of palatal wound sites: a planimetrical and cytological study. Journal of investigative and clinical dentistry, 2(4), 248-258. https://doi.org/10.1111/j.2041-1626.2011.00072.x

Ranjith, A., Niranjana, J. M., \& Baiju, K. V. (2021). Adjunctive benefit of ozonized water irrigation with mechanical debridement in the management of Stage III periodontitis: A randomized controlled clinical and biochemical study. International journal of dental hygiene, 10.1111/idh.12547. Advance online publication. https://doi.org/10.1111/idh.12547

Rapone, B., Ferrara, E., Corsalini, M., Converti, I., Grassi, F. R., Santacroce, L., Topi, S., Gnoni, A., Scacco, S., Scarano, A., \& Delvecchio, M. (2020). The Effect of Gaseous Ozone Therapy in Conjunction with Periodontal Treatment on Glycated Hemoglobin Level in Subjects with Type 2 Diabetes Mellitus: An Unmasked Randomized Controlled Trial. International journal of environmental research and public health, 17(15), 5467. https://doi.org/10.3390/ijerph17155467

Rosell, A. P., Femenías, J. L. C., \& Capote, N. J. (2019). Utilidad del oleozón tópico en la gingivitis crónica fibroedematosa. Revista Médica Electrónica, 41(1), 54-62.

Saglam, E., Alinca, S. B., Celik, T. Z., Hacisalihoglu, U. P., \& Dogan, M. A. (2019). Evaluation of the effect of topical and systemic ozone application in periodontitis: an experimental study in rats. Journal of Applied Oral Science, 28. https://doi.org/10.1590/1678-7757-2019-0140

Talmaç, A. C., \& Çalişir, M. (2021). Efficacy of gaseous ozone in smoking and non-smoking gingivitis patients. Irish journal of medical science, 190(1), 325333. https://doi.org/10.1007/s11845-020-02271-x

Taşdemir, Z., Alkan, B. A., \& Albayrak, H. (2016). Effects of Ozone Therapy on the Early Healing Period of Deepithelialized Gingival Grafts: A Randomized Placebo-Controlled Clinical Trial. Journal of periodontology, 87(6), 663-671. https://doi.org/10.1902/jop.2016.150217

Tasdemir, Z., Oskaybas, M. N., Alkan, A. B., \& Cakmak, O. (2019). The effects of ozone therapy on periodontal therapy: A randomized placebo-controlled clinical trial. Oral diseases, 25(4), 1195-1202. https://doi.org/10.1111/odi.13060

Yilmaz, S., Algan, S., Gursoy, H., Noyan, U., Kuru, B. E., \& Kadir, T. (2013). Evaluation of the clinical and antimicrobial effects of the Er:YAG laser or topical gaseous ozone as adjuncts to initial periodontal therapy. Photomedicine and laser surgery, 31(6), 293-298. https://doi.org/10.1089/pho.2012.3379 